\title{
Phenotypic and genotypic characterization of antibiotic-resistant in Escherichia coli isolates from patients with diarrhea
}

\author{
${\text { Mojtaba Bonyadian }{ }^{1 *} \text {, Sara Barati², Mohammad Reza Mahzounieh }}^{3}$ \\ ${ }^{\prime}$ Department of Health and Food Quality Control, Institute of Zoonoses Research, Shahrekord University, \\ Shahrekord, Iran \\ ${ }^{2}$ Department of Microbiology, Ahvaz Branch, Islamic Azad, University, Ahvaz, Iran \\ ${ }^{3}$ Department of Pathobiology, Institute of Zoonoses Research, Shahrekord University, Shahrekord, Iran
}

Received: February 2019, Accepted: May 2019

\begin{abstract}
Background and Objectives: Escherichia coli is a common enteric pathogen of human and livevestock. Antibiotic resistance is the main concern of public health. The aim of this study was to detect this bacterium in stool samples of diarrheal patients and identify the phenotypic and genotypic characterizations of antibiotic-resistant isolates such as dfrAl, sull, citm, tetA, qnr, aac(3)-IV in Shahrekord.

Materials and Methods: Two hundred fifty diarrheal stool samples from patients were collected. Microbiological and biochemical examinations were done to detect E. coli. Phenotypic and genotypic antibiotic resistance of the isolates were determined using dick diffusion method and polymerase chain reaction (PCR), respectively.

Results: Among 114 E. coli isolates, the least resistance was for gentamicin $(0 \%)$ and the most resistance was for trimethoprim $(79.8 \%)$. The resistance to sulfamethoxazole, ciprofloxacin, ampicillin, and tetracycline were $71.05 \%, 10.5 \%, 52.63 \%$, and $3.5 \%$ respectively. The results of PCR assay revealed that 10 isolates contain sull, 49 isolates harbor citm, 8 isolates tetA, 36 isolates $d f r A 1,11$ isolates qnr genes but there was no isolate with aac(3)-IV gene. In comparison between phenotypic and genotypic of the isolates revealed that citm, tetA, $d f r A 1$, qnr, sull, aac(3)-IV genes covered $42.98 \%, 7.01 \%, 31.57 \%, 9.64 \%$, $8.7 \%, 0 \%$ of the antibiotic resistance, respectively.

Conclusion: Our results revealed that all isolates harbor one or more antibiotic resistance genes and that the PCR is a fast practical and appropriate method to determine the presence of antibiotic resistance genes.
\end{abstract}

Keywords: Antibiotics resistance; Phenotypic; Genotypic; Escherichia coli; Diarrhea

*Corresponding author: Mojtaba Bonyadian, Ph.D, Department of Health and Food Quality Control, Institute of Zoonoses Research, Shahrekord University, Shahrekord, Iran.

Telefax: +98-381 4424427

Email: boniadian@vet.sku.ac.ir

\section{INTRODUCTION}

There is worldwide concern about the appearance and rise of bacterial resistance to commonly used antibiotics. In this regard program for monitoring, resistance has been implemented in many countries $(1,2,3)$. It has been demonstrated that diarrhoeagen- 
ic E. coli strains are categorized into specific groups based on virulence properties, mechanisms of pathogenicity, clinical syndromes, and distinct $\mathrm{O}$ : $\mathrm{H}$ serotypes (4). A number of E. coli strains are recognized as important pathogens of colibacillosis in poultry and some of them can cause severe human diseases such as hemorrhagic colitis and hemolytic uremic syndrome (5-7). The six main categories include enteropathogenic $E$. coli (EPEC), enterotoxigenic E. coli (ETEC), enteroinvasive E. coli (EIEC), enteroaggregative E. coli (EAEC), enterohemorrhagic E. coli (EHEC or STEC), diffuse adhering E. coli (DAEC) (8). Enterotoxigenic E. coli is a common cause of diarrheal disease in developing countries. The enteric pathogens are often resistant to multiple antibiotics.

However, a large number of outbreaks of enterotoxins have also been associated with the consumption of contaminated drinking water or contact with recreational water $(5-7,9)$.

E. coli infections as a cause of disease have shown a marked increase in many countries.

$E$. coli use as an index for determining fecal contamination in water and foods. Foods contaminated with antibiotic-resistant bacteria could be a major threat to public health as there is possibility that genes encoding antibiotic resistance determinants that are carried on mobile genetic elements may be transferred to other bacteria of human clinical significance. E. coli is a candidate vehicle for such transfers because of its diversity and also because it survives as common flora in the gastrointestinal tracts of both humans and animals. They are sensitive to selection pressure exerted by antibiotic usage and carry genetic mobile elements to achieve such transmission (10). In addition, the lack of stringent controls on antimicrobial use in human health and particularly in animal production systems increase the risk of foodborne microbes harboring an array of resistance genes. In many countries for the purpose of protecting the health of humans as well as animals, treatment of illnesses caused by this bacterium often requires antimicrobial therapy $(1,2,3)$. The decision to use antimicrobial therapy depends on the susceptibility of the microorganisms and the pharmacokinetics of the drug for achieving the desired therapeutic concentration at the site of infection and thus clinical efficacy (11).

This study was conducted to baseline profile of antimicrobial resistance of $E$. coli isolated from pa- tients with diarrhea. We undertook this study to identify the presence of isolates of E. coli from stool samples from patients with diarrhea in Shahrekord and to characterize the genes and comparison between the phenotypic and genotypic characterization of antibiotic-resistant strains.

\section{MATERIALS AND METHODS}

Sample collection. A total of 250 diarrheal fecal samples from the patients were collected in Hajar hospital of Shahrekord. The questionnaire was prepared and filled by patients.

Isolation of $\boldsymbol{E}$. coli. MacConky agar and Salmonella Shigella agar (Merck, Germany), were used to detect E. coli. A swab of fecal sample was cultured on MCA and SS agar and incubated for $24 \mathrm{~h}$ at $37^{\circ} \mathrm{C}$. Complete biochemical identification (Gram staining, oxidase, indole, Simon's citrate and urease) was used to identify the isolated organism. Bacteriological examinations were done on non-lactose fermenting colonies to confirm the major causes of diarrhea e.g. Salmonellae and Shigella $(12,13)$.

Antimicrobial susceptibility. Antimicrobial susceptibility testing was carried out by the disk diffusion method according to the Clinical and Laboratory Standard Institute guidelines (CLSI, 2018) $(14,15)$.

Detection of citm, tetA, dfrA1, qnr, sul1, aac (3)IV genes. Total DNA of the isolates was extracted using the Genomic DNA purification kit (Fermentas, Germany). The isolated DNA was suspended in $50 \mathrm{ul}$ of Tris-EDTA (TE) buffer at $\mathrm{pH}$ 8. Two microlitres of eluting were used as DNA template in PCR assay. PCR was performed using 6 primer sets (Cinagen, Iran) that detect antibiotic resistance genes.

The set of primers used for each gene is shown in Table 1.

The presence of genes associated with resistance to ampicillin ( $\mathrm{citm})$, tetracycline (tetA) trimethoprim $(d f r A l)$, quinolones (qnr), gentamicin (aac(3)-IV) and sulfonamides (sull) was determined by PCR. Reactions were performed in a total volume of $25 \mu \mathrm{l}$, including $1.5 \mathrm{ml} \mathrm{MgCl}, 50 \mathrm{mM} \mathrm{KCl}, 10 \mathrm{mM}$ Tris$\mathrm{HCl}$ (pH 9.0), 0.1\% Triton X-100, $1 \mu$ l of each dNTP, $1 \mu \mathrm{l}$ primers, $0 / 2$ IU of Taq DNA polymerase (Fermentas), and $2 \mu \mathrm{l}$ of DNA. Amplification reactions 
MOJTABA BONYADIAN ET AL.

Table 1. Primers sequences used in PCR and expected sizes of products

\begin{tabular}{|c|c|c|c|}
\hline Target & Sequence (5-3) & Size bp & Annealing Temp \\
\hline $\operatorname{Aac}(3)-I V-F$ & CTT CAG GAT GGC AAG TTG GT & 286 & 54 \\
\hline $\operatorname{Aac}(3)-I V-R$ & TCA TCT CGT TCT CCG CTC AT & 286 & \\
\hline Sull-F & TTC GGC ATT CTG AAT CTC AC & 822 & 47 \\
\hline Sull-R & ATG ATC TAA CCC TCG GTC TC & 822 & \\
\hline$C I T M-F$ & TGG CCA GAA CTG ACA GGC AAA & 462 & 49 \\
\hline$C I T M-R$ & TTT CTC CTG AAC GTG GCT GGC & 462 & \\
\hline TetA-F & GGT TCA CTC GAA CGA CGT CA & 577 & 55 \\
\hline TetA-R & CTG TCC GAC AAG TTG CAT GA & 577 & \\
\hline dfrAl-F & GGA GTG CCA AAG GTG AAC AGC & 367 & 49 \\
\hline dfrAl-R & GAG GCG AAG TCT TGG GTA AAA AC & 367 & \\
\hline$Q n r-F$ & GGG TAT GGA TAT TAT TGA TAA AG & 670 & 55 \\
\hline$Q n r-R$ & CTA ATC CGG CAG CAC TAT TTA & 670 & \\
\hline
\end{tabular}

were carried out using a DNA thermo-cycler (Bio$\mathrm{Rad})$ as follows: Five min at $95^{\circ} \mathrm{C}, 35$ cycles each consisting of $1 \mathrm{~min}$ at $94^{\circ} \mathrm{C}, 30 \mathrm{~s}$ at $\sim 55^{\circ} \mathrm{C}$ and $1 \mathrm{~min}$ at $72^{\circ} \mathrm{C}$, followed by a final extension step of $5 \mathrm{~min}$ at $72^{\circ} \mathrm{C}$. Amplified samples were analyzed by electrophoresis in $1.5 \%$ agarose gel and stained by ethidium bromide. A molecular weight marker with $100 \mathrm{bp}$ increments (100 bp DNA ladder, Fermentas) was used as a size standard $(10,16)$.

\section{RESULTS}

One hundred fourteen (34.2\%) lactose fermenting and pink colonies were isolated on MCA and were confirmed as $E$. coli by biochemical and microbiological tests. Also, the antibiotic resistance of the isolates was evaluated. In phenotype, the least resistance was for gentamicin $(0 \%)$ and the most resistance was for trimethoprim $(79.8 \%)$. The resistance to cotrimoxazole, ciprofloxacin, ampicillin, and tetracycline was found in $71.05 \%, 10.5 \%, 52.63 \%, 3.5 \%$ of isolates respectively (Table 2).

In PCR assay, 10 isolates contain sull, 49 isolates contain citm, 8 isolates contain tetA, 36 isolates contain $d f r A 1,11$ isolates contain $q n r$ genes but there was no isolate with $\operatorname{aac}(3)-I V$ gene (Table 3).

Also, the results showed that the single resistance found in $27.19 \%$, double resistance in $18.42 \%$, triple resistance in $6.14 \%$ and quadruple resistance in $4.38 \%$ of the isolates (Table 4).

Comparison between phenotypic and genotypic of the isolates revealed that citm, tetA, dfrAl, qnr, sull, aac(3)-IV genes covered $42.98 \%, 7.01 \%, 31.57 \%$,

Table 2. Percentage of antibiotic resistance of $E$. coli isolated from diarrheal samples

\begin{tabular}{llll}
\hline Antibiotics & $(\mathbf{S})$ & $(\mathbf{I})$ & $(\mathbf{R})$ \\
\hline Tetracyclin & 31.5 & 64.9 & 3.5 \\
Gentamicin & 89.4 & 10.5 & 0 \\
Ampicillin & 12.28 & 35.08 & 52.63 \\
Ciprofloxacin & 75.4 & 14.03 & 10.5 \\
Sulphametoxazole & 7.01 & 21.92 & 71.05 \\
Trimethoprim & 19.29 & 0.87 & 79.8 \\
\hline
\end{tabular}

S: Susceptible, I: Intermediate, R: Resistance

Table 3. Antibiotic resistance genes in E. coli isolated from diarrheal samples

\begin{tabular}{llllll}
\hline $\boldsymbol{q n} \boldsymbol{r}$ & $\boldsymbol{d} \boldsymbol{f r A 1}$ & tetA & $\boldsymbol{c i t M}$ & sul1 & $\boldsymbol{a a c ( 3 ) - I V}$ \\
\hline 11 & 36 & 8 & 49 & 10 & 0 \\
$(9.64 \%)$ & $(31.57 \%)$ & $(\% 7.01)$ & $(42.98 \%)$ & $(8.7 \%)$ & $(0 \%)$
\end{tabular}


Table 4. Presence of multiple resistance genes in isolated E. coli

\begin{tabular}{llll}
\hline Number & Gene & & $\begin{array}{l}\text { Type of } \\
\text { resistance }\end{array}$ \\
\hline 9 & $d f r A 1$ & $31(\% 27.19)$ & Single \\
17 & citm & & \\
5 & $q n r$ & $21(18.42 \%)$ & Double \\
16 & $d f r A 1-C i t m$ & & \\
1 & $d f r A 1-S u l 1$ & & \\
2 & Sull-Citm & & \\
2 & qnr-citm & & \\
2 & dfrAl-Sul1-citm & $7(6.14 \%)$ & Triple \\
3 & dfrA1-tet-citm & & \\
1 & Sull-citm-tet & & \\
1 & Sull-Citm-Qnr & & \\
2 & dfrAl-sul1-citm-tet & $5(4.38 \%)$ & Quadruple \\
1 & dfrAl-sull-citm-qnr & & \\
2 & dfrAl-citm-tet-qnr & & \\
\hline
\end{tabular}

$9.64 \%, 8.7 \%, 0 \%$ of the antibiotic resistance in the isolates, respectively.

\section{DISCUSSION}

Our findings showed that $E$. coli were the major cause of human enteric infections in this area of Iran. A lot of researches have been run in recent years on detection, identification, and molecular characterization of antibiotic resistance genes, which has led to a more accurate assessment of the role of these bacteria in human disease outbreaks and the transmission of infection from an animal reservoir. Most information on risk factors associated especially $E$. coli infection has come from outbreak investigations. Among identified dietary risk factors, foods of bovine origin, particularly undercooked ground beef, have been a frequently implicated source. Non-dietary risk factors including person-to-person transmission in day-care settings or swimming in contaminated water have also been documented $(17,18)$. In our study, about half of the isolated E. coli belonged to citm gene, and more than of $40 \%$ of the isolates were positive for the $d f r A$ gene, but none of them carried aac(3)-IV gene. Also, more than $10 \%$ of the isolates were positive for sull, tetA, qnr genes. Lien et al. (2018) reported that resistance to at least one antibiotic was detected in $83 \%$ of $E$. coli isolated from hospital wastewater in
Vietnam; multidrug resistance was found in $32 \%$ of the isolates. The highest resistance prevalence was found for co-trimoxazole $(70 \%)$ and the lowest for imipenem (1\%), (19). Hassan (2018) revealed that all the E. coli strains isolated from patients and food were highly resistance to penicillin, amoxicillin-clavulanic and erythromycin with a percentage of $100 \%$, while the resistance to gentamicin, ampicillin, oxytetracycline, chloramphenicol, norfloxacin, trimethoprim, and nalidixic acid were $83 \%, 75 \%$, $65.3 \%, 55.8 \%, 36.5 \%, 30.7 \%$ and $26.9 \%$ respectively (20). Weiss et al. (2018) reported that $29.6 \%$ of the isolated E. coli were resistant to at least one of 11 antibiotics tested. The frequency of resistance reached $20.3 \%$ of isolates for trimethoprim-sulfamethoxazole but was nearly zero for the less commonly available antibiotics ciprofloxacin $(0.4 \%)$, gentamicin $(0.2 \%)$, and ceftiofur $(0.1 \%)$. The frequency of resistance was $57.4 \%$ in isolates from people, $19.5 \%$ in isolates from domestic animals, and $16.3 \%$ in isolates from wild nonhuman primates (21).

A study on $E$. coli isolated from fecal samples of children in Taiwan (2018) showed that the rates of resistance to ampicillin, amoxicillin + clavulanate, trimethoprim-sulfamethoxazole, and cefazolin were 70, 65.6, 47.1 and 32.5\%, respectively (22).

Shehata, et al. (2017) indicated that all the isolated E. coli from fecal samples of human and chicken in Egypt show high resistance to multiple antibiotics. Strains of E. coli from human were highly resistant to ampicillin (72.7\%). The antibiotic resistance genes $b l a_{\text {OXA }}, s h v, d h f r V, d h f r I, c m l A$ and catl were detected in both human isolates and animal isolates (23).

Our study revealed that the presence of $E$. coli in diarrheal stool samples of patients emphasizing the need of using protocol for detection of all serotypes of $E$. coli from human, animals and meat products in clinical and food microbiology laboratories. The mechanism of spread of antibiotic resistance from food animals to humans remains controversial.

However, veterinary practitioner has a limited choice of antimicrobials for use in the poultry industry due to antimicrobial resistance issues and human health concerns.

Moreover, the repeated and unsuitable use of antibiotics has led to an increasing rate of antimicrobial resistance (16). Now different PCR protocols for detection of $E$. coli are available making a diagnosis of E. coli infections possible.

In conclusion, our results showed that antibiot- 
ic-resistant $E$. coli was the main bacterial pathogen causing diarrhea in this part of Iran and advanced detection methods like PCR need to be used in microbiology to confirm the antibiotic resistance genes as well as disk diffusion method.

\section{REFERENCES}

1. Aarestrup FM. Monitoring of antimicrobial resistance among food animals: principles and limitations. $J$ Vet Med B Infect Dis Vet Public Health 2004; 51: 380-388.

2. Cizman M. The use and resistance to antibiotics in the community. Int J Antimicrob Agents 2003; 21: 297-307.

3. Li D, Liu B, Chen M, Guo D, Guo X, Liu F, et al. A multiplex PCR method to detect Escherichia coli serogroups associated with urinary tract infections. $J \mathrm{Mi}$ crobiol Methods 2010; 82: 71-77.

4. Meng J, LeJeune J, Zhao T, Doyle M. Enterohemorrhagic Escherichia coli, p 287-309. In Doyle M, Buchanan R (ed), Food Microbiology. 2013, ASM Press, Washington, DC.

5. Chansiripornchai N. Comparative efficacy of enrofloxacin and oxytetracycline by different administration methods in broilers after experimental infection with avian pathogenic Escherichia coli. Thai J Vet Med 2009; 93: 231-236.

6. Ferens WA, Hovde CJ. Escherichia coli O157:H7: animal reservoir and sources of human infection Foodborne Pathog Dis 2011; 8: 465-487.

7. Tarr PI, Gordon CA, Chandler WL. Shiga-toxin-producing Escherichia coli and haemolytic uraemic syndrome. Lancet 2005; 365: 1073-1086.

8. Kaper JB, Nataro JP, Mobley HL. Pathogenic Escherichia coli. Nat Rev Microbiol 2004; 2:123-140.

9. Keene WE, McAnulty JM, Hoesly FC, Williams LP Jr, Hedberg K, Oxman GL, et al. A swimming-associated outbreak of hemorrhagic colitis caused by Escherichia coli O157:H7 and Shigella sonnei. N Engl J Med 1994; 331: 579-584.

10. Sandvang D, Aarestrup FM. Characterization of aminoglycoside resistance genes and class 1 integrons in porcine and bovine gentamicin-resistant Escherichia coli. Microb Drug Resist 2000; 6:19-27.

11. McKellar QA, Sanchez Bruni SF, Jones DG. Pharmacokinetic/pharmacodynamic relationships of antimicrobial drugs used in veterinary medicine. J Vet Pharma- col Ther 2004; 27: 503-514.

12. Jawetz EJL. Review of medical microbiology. 26th ed, 2013; 162-180.

13. Kehl SC. Role of the laboratory in the diagnosis of enterohemorrhagic E. coli infections. J Clin Microbiol 2002; 40: 2711-2715.

14. Momtaz H, Rahimi E, Moshkelani S. Molecular detection of antimicrobial resistance genes in E. coli isolated from slaughtered commercial chickens in Iran. Vet Med 2012; 57: 193-197.

15. Sandvang D, Aarestrup FM. Characterization of aminoglycoside resistance genes and class 1 integrons in porcine and bovine gentamicin-resistant Escherichia coli. Microb Drug Resist 2000; 6:19-27.

16. Mooljuntee S, Chansiripornchai P, Chansiripornchai N. Prevalence of the cellular and molecular antimicrobial resistance against $E$. coli isolate from Thai broilers. Thai J Vet Med 2010; 40: 311-315.

17. Desmarchelier P. Enterohemorrhagic Escherichia coli-The Australian Perspective. J Food Prot 1997; 60: 1447-1450.

18. Hu Y, Zhang Q, Meitzler JC. Rapid and sensitive detection of Escherichia coli O157:H7 in bovine faeces by a multiplex PCR. J Appl Microbiol 1999; 87: 867876.

19. Lien TQ, Lan PT, Chuc NTK, Hoa NQ, Nhung PH, Thoa NTM, et al. Antibiotic resistance and antibiotic resistance genes in Escherichia coli isolates from hospital Wastewater in Vietnam. Int J Environ Res Public Health 2017; 14(7): E699.

20. Hassan A. Molecular characterization of antibiotic resistant Escherichia coli isolates recovered from food samples and outpatient Clinics, KSA. Saudi J Biol Sci 2018; 25: 928-931.

21. Weiss D, Wallace RM, Rwego IB, Gillespie TR, Chapman CA, Singer RS, et al. Antibiotic-resistant Escherichia coli and class 1 integrons in humans, domestic animals, and wild primates in Rural Uganda. Appl Environ Microbiol 2018; 84(21): e01632-18.

22. Huang IF, Lee WY, Wang JL, Hung CH, Hu HH, Hung WY, et al. Fecal carriage of multidrug-resistant Escherichia coli by community children in southern Taiwan. BMC Gastroenterol 2018; 18: 86.

23. Shehata ME, Gamal M, Amira HM, Hesham MS. Molecular and phenotypic characterization of some antimicrobial resistance genes in Escherichia coli isolated from human and Broiler Chickens. Int J Curr Microbiol App Sci 2016; 5: 953-965. 